\title{
A RESILIÊNCIA EM MULHERES DE UM BAIRRO POPULAR DE SALVADOR, BAHIA: RECURSOS PESSOAIS E CONTEXTUAIS ${ }^{*}$
}

\author{
WOMEN'S RESILIENCE IN A POPULAR NEIGHBOURHOOD LOCATED IN \\ SALVADOR, BAHIA: PERSONAL AND CONTEXTUAL RESOURCES
}

Maria Célia Correa Gomes*

Elaine Pedreira Rabinovich ${ }^{* *}$ Ana Cecília de Sousa Bastos ${ }^{* * *}$

Gomes MCC, Rabinovich EP, Bastos AcdS. A resiliência em mulheres de um bairro popular de Salvador, Bahia: recursos pessoais e contestuais. Rev Bras Cresc Desenv Hum 2005; 15(3):49-56.

Resumo: Este é um estudo qualitativo e exploratório que visou caracterizar os recursos pessoais e contextuais utilizados ante abandono, violência em relação a si mesma e aos seus filhos, desemprego e doenças, por mulheres consideradas "resilientes" por apresentarem habilidade de superar de forma socialmente positiva as adversidades. Procurou identificar como tais mulheres, quando crianças e adolescentes, perceberam e exploraram seu entorno quanto ao seu funcionamento e às oportunidades por ele oferecidas, e que recursos pessoais e contextuais utilizaram. Foram escolhidas cinco participantes de um grupo de "Conversa de Família", realizado em um Centro Educativo, no Subúrbio Ferroviário da cidade de Salvador, Bahia. Foi realizada uma entrevista semi-estruturada quanto à história de vida e à rede sociométrica. A análise foi ancorada em uma perspectiva ecológica do desenvolvimento humano, que considera a pessoa em contexto e processos desenvolvimentais no tempo e na abordagem psicodramática. Os resultados do estudo indicaram uma "resiliência de sobrevivência" alicerçada sobre o próprio desempenho, em que as dificuldades se tornaram meios para o seu sucesso como pessoa. Mostrou a presença de figuras, reais ou imaginárias, e a importância de terem tido uma rede relacional, dentro e/ou fora da família, e de terem podido transitar pela mesma, posto que essas formas de relacionamento irão servir de base para relacionamentos futuros. Alguns traços comuns sobressaíram: confiança em si mesmas e em sua capacidade de encontrar caminhos viáveis, persistência, boa imagem de si próprias, não ter ressentimento e manter o humor. As redes de apoio estavam presentes em todas as histórias, possibilitando a sobrevivência da família de origem, posteriormente a sua e, quando adultas, elas próprias sendo a rede para os seus filhos, netos, afilhados, vizinhos.

Palavras-chave: Resiliência. Contexto. Apego. Desenvolvimento. Família.

\section{INTRODUÇÃO}

A resiliência pode ser definida como a capacidade que um indivíduo tem de resolver de maneira adequada e positiva os reveses que aparecem em seu caminho e sair deles transfor-

\footnotetext{
\# Dissertação de Mestrado em Família na Sociedade Contemporânea da Universidade Católica do Salvador, localizado na Rua Ilhéus 205 Salvador, Bahia. CEP 41940-3. Orientado por Elaine Pedreira Rabinovich, profa. do MestradoUCSAL, e por Ana Cecília Bastos, Psicologia-UFBA. Endereço para correspondência: mariacelia@br.inter.net

* Mestre em Ciências da Família na Sociedade Contemporânea, Universidade Católica do Salvador (UCSAL). Trabalho apresentado em 28/04/2005.

** Doutora em Psicologia Social, Universidade de São Paulo (USP). (UCSAL).

*** Doutora em Psicologia, Universidade de Brasília (UnB).
} 
mado. É a habilidade de transformar comportamentos, conseguir mudanças socialmente aceitáveis e poder projetar o futuro ${ }^{1}$.

Crianças e adultos passam por situações adversas durante seu processo desenvolvimental, tais como: serem discriminados por um dos pais ou ambos, sofrerem privações tanto emocionais quanto físicas, perderem entes queridos por morte ou separação, morarem em região considerada de risco em que sua integridade física corre perigo, não terem tido um apego seguro ${ }^{2}$ e, no entanto, conseguem superar todos esses percalços e se tornam adultos sadios. Quais serão os fatores que os levam ao sucesso?

Para Rutter ${ }^{3}$, esses processos teriam lugar através do tempo, combinando atributos da criança e seu ambiente familiar, social e cultural. A resiliência não pode ser pensada como um atributo inato ou adquirido durante o seu desenvolvimento, mas como um processo interativo entre esta e seu meio. Nessa perspectiva, assume-se não apenas uma inter-relação entre aspectos biológicos e socioculturais, mas a primazia da participação de outros sociais na transmissão da cultura que, em grande parte, se realiza no âmbito da vida cotidiana ${ }^{4}$.

O espaço desenvolvimental, deste modo, consiste em um contexto, complexo e interativo, de pessoas, de objetivos, de valores, de significados, de história e de tempo. A forma como esses elementos interagem entre si e com a criança vai criar padrões de ações que virão como respostas a este contexto. Os padrões podem ser mantidos ou modificados, definindo formas de atuar que servirão de bases para outras ações que o acompanharão por todo o processo do seu desenvolvimento, desde a infância até a velhice.

Bowlby ${ }^{2}$ enfatiza que as experiências in- fantis na família, assim como a relação com a mãe desde os primeiros meses de vida, são os fatores que mais efeitos exercem sobre o desenvolvimento. Como condições que poderão propiciar ou não o vínculo com uma figura de referência afetiva, estariam: a sensibilidade desta figura para responder aos sinais do bebê; a quantidade e natureza da interação entre os componentes do par. ${ }^{+}$

De fato, Bowlby ${ }^{5}$ destaca especialmente a relação de apego que se estabelece entre a criança e o cuidador primário (monotropia). No entanto, coloca que as crianças também dirigem o comportamento de apego para outras figuras chamadas de figuras subsidiárias de apego. Contudo, a ênfase da estrutura da sua teoria está na relação de apego que se estabelece entre a criança e o cuidador primário.

Contudo, o próprio Bowlby ${ }^{5}$ reconhece que diferentes cuidadores poderiam atuar em função de diferentes costumes:

Cada comunidade tem suas próprias tradições envolvendo a pessoa que normalmente assume essas funções indispensáveis aos cuidados com a criança. Freqüentemente são os pais que assumem o papel mais importante, mas isto nem sempre acontece. As tradições vari$\mathrm{am}$, principalmente quanto à medida que são aceitáveis substitutos para os pais (p. 79).

Deste modo, o comportamento de todo indivíduo dentro da família está relacionado com e depende do comportamento de todos os outros, tanto influencia quanto é influenciado por outros.

Por meio da convivência, a criança vai construindo e firmando sua identidade, tendo noção do papel que tem no espaço familiar e de sua posição na rede que nele se forma.

Para Moreno ${ }^{6}$, papel é a unidade de condutas inter-relacionais observáveis, num momen-

Quantidade de vezes que a mãe interage com a criança acordada, pelo olhar, tato, pegando-a no colo, estando atenta às necessidades e reação da criança a essas interações, ao afastamento da mãe, à aproximação de estranhos, quando a mãe está perto e quando não está. A reação da mãe é importante quando a criança faz explorações ou amizades com outras pessoas. 
to específico em resposta a uma situação específica, na qual outras pessoas ou objetos estão envolvidos.

De modo concorde a Moreno ${ }^{6}$, para Bronfenbrenner" "um papel é uma série de atividades e relações esperadas de uma pessoa que ocupa uma determinada posição na sociedade e de outros em relação àquela pessoa". Quando se fala de papel, não se pode esquecer de que ele pressupõe inter-relações e ações com outros papéis e que uns influenciam os outros.

Ter consciência do seu papel e do seu valor tanto na comunidade familiar quanto na comunidade social pode respaldar a auto-estima e confiança, considerados atributos da resiliência.

Seligman ${ }^{8}$ contribui para a presente discussão com o conceito de "otimismo aprendido" em que, se desde cedo uma pessoa aprender que a sua forma de reagir aos acontecimentos vai fazer diferença, ela provavelmente desenvolverá comportamentos mais voltados a enfrentar as adversidades e, possivelmente, estará com esta atitude construindo um comportamento esperançoso na forma como se posicionará nos diversos acontecimentos de sua vida.

O humor, como causa e/ou consequiência dos aspectos anteriormente apontados, é um aspecto com frequiência ressaltado, pois ele levaria as pessoas a encarar os fatos não como trágicos, mas como dramáticos; pois, se a tragédia representa uma certa imobilidade, o drama significa ação e, portanto, possibilidade de mudanças.

Em apoio a essa visão, Moreno ${ }^{6}$ considera o homem um ser espontâneo e criativo por excelência, podendo, a partir de situações já conhecidas, criar novas formas de se colocar no mundo, ou seja, de estar-em-relação-com. Vê o homem como um ser capaz, que acredita em si e que tem a possibilidade de desenvolver sua auto-estima.

Nessa mesma direção, Lewis ${ }^{9}$ propõe um modelo contextual que tem como premissa bá- sica ser o comportamento social determinado e controlado pela estrutura social. Mudandose a estrutura social muda-se o comportamento social. Isto significaria que as relações iniciais que os sujeitos mantêm nos seus grupos sociais e familiares não são determinantes nem estruturantes definitivamente da sua história. Sua história poderá ser modificada, se as estruturas e as bases sociais forem alteradas e se os sujeitos se disponibilizarem para isso.

Dessa perspectiva, a resiliência não pode ser considerada um atributo absoluto nem estável. Uma pessoa pode ser resiliente numa determinada situação e contexto e não ser em outra situação em que haja variação de um desses elementos ou de ambos. $\mathrm{O}$ apego, igualmente, seria um processo dinâmico e necessitaria, para a sua manutenção, de condições contextuais 9 .

Por sua vez, de acordo com Bronfenbrenner ${ }^{7}$, os contextos são constituídos como estruturas abertas, dinâmicas e mutáveis e se concretizam desde as relações diretas entre as pessoas e destas com os objetivos próximos (microssistema) até as influências fisicamente distantes que vão interferir não só na organização de cada contexto, mas também nas interações entre os sujeitos e seu ambiente e nas interações entre os diversos contextos (mesossistema; macrossistema; exossistema).

Nesses contextos sociais, criados historicamente pelas pessoas e pelas relações entre elas, existem fatores externos que limitam ou definem suas ações a partir de situações difíceis de serem enfrentadas e rompidas. Impõe-se, pois, estudar o comportamento-em-contexto, para que se possa entender o comportamento da criança e sua trajetória desenvolvimental9 ${ }^{9}$.

Deste modo situações de risco seriam eventos negativos da vida em que as crianças, possivelmente, poderão apresentar comportamentos vulneráveis em relação às mesmas, entendendo-se por vulnerabilidade "uma intensificação da reação frente a estímulos que em 
circunstâncias normais conduzem a uma desadaptação"3.

Como contraponto à vulnerabilidade, terse-iam os fatores de proteção que, segundo o referido autor, atuam como um fator de atenuação, sendo considerados como mecanismos de proteção.

Para Masten e Garmezy ${ }^{10}$, haveria três importantes fatores de proteção ao desenvolvimento da criança: características de personalidade, tais como autonomia, auto-estima e orientação social positiva; coesão familiar e sabedoria para resolver conflitos; disponibilidade de sistemas externos de apoio que encorajem e reforcem a capacidade da criança para lidar com as circunstâncias da vida. Além desses, como aponta Kaloustian ${ }^{11}$, as famílias têm o direito de contar com a solidariedade social vista como uma dimensão mais ampla da noção de vínculo.

Em toda sociedade, existem estruturas que funcionam como redes de apoio, complementando, em alguns casos, funções corriqueiras, em outros, funções mais especializadas do processo de desenvolvimento, ampliando as famílias e a comunidade como um todo: Unidades de Saúde, Escola, Locais de Cultos Religiosos, Grupos Comunitários e, a própria vizinhança.

Dentre os riscos psicossociais, Yunes e Szymanski ${ }^{12}$ destacam a privação econômica e chegam a referir a universalidade de pobreza e miséria como fatores de risco e vulnerabilidade.

A partir do que foi exposto e com o objetivo de refletir sobre a resiliência em mulheres de um bairro popular, quanto a como usaram os recursos pessoais e contextuais disponíveis e também da participação ativa da família na transmissão de valores e critérios de orientação de conduta, assim como a significação afetiva de cada um dos membros que compõe este grupo, foi concebido este estudo desenvolvido com mulheres do grupo "Conversa de Família”, em um Centro Educativo do Bairro de Novos Alagados, Subúrbio Ferroviário da cidade de Salvador, Bahia.

Assim, o objetivo do presente estudo foi caracterizar os recursos pessoais e contextuais que mulheres, supostas como sendo pessoas resilientes, utilizaram frente a eventos críticos tais como: abandono, violência, desemprego e doenças, em relação a si mesma e aos seus filhos.

\section{MÉTODO}

Participaram deste estudo cinco mulheres, supostas pessoas resilientes, que atenderam aos seguintes critérios: capacidade de conduzir as suas vidas; tomar decisões socialmente aceitáveis; saber identificar e fazer uso dos recursos disponíveis na sua comunidade; senso de humor; perseverança; crença no futuro e criatividade.

Os dados foram coletados em duas etapas. $\mathrm{Na} 1^{\mathrm{a}}$ etapa, foram consideradas todas as mulheres que apresentaram comportamento supostos resilientes, deduzidos dos fatos por elas relatados acerca de suas histórias de vida e de suas famílias, de suas atitudes durante as atividades desenvolvidas e da forma como relatavam que se comportavam no dia a dia. A $2^{\text {a }}$ etapa foi constituída pelo estudo de cinco mulheres que preencheram os critérios acima citados.

Realizada uma entrevista por meio de um roteiro semi-estruturado. Os dados referentes ao objetivo foram qualitativamente considerados.

As entrevistas foram analisadas face aos objetivos acima relatados utilizando-se o método de observação empírica de categorias.

A seguir, à guisa de exemplo, será apresentado um dos casos estudados e algumas considerações referentes ao conjunto dos cinco depoimentos. 


\section{Um Caso do Estudo: A história de Lúcia}

Caçula de uma família composta por mãe, pai e cinco irmãos, a mãe era lavadeira e o pai catador de dendê.

Quando estava com 6 anos, seus pais tiveram uma briga terrível e sua mãe teve que sair de casa e nunca mais pode voltar. Após este fato, seu pai ficou com muita raiva da mulher e passou a maltratá-los muito, passaram por muitas privações, os vizinhos "é que ajudavam escondido dele".

Já com 5 anos ajudava suas irmãs a lavar roupa e a encher os tonéis dos outros. Foi para escola com 11 anos. O pai colocou-os para estudar, fazia questão disso, mas não dava material nenhum. "Eu não tinha nada, nem um lápis, meus colegas é que quando acabavam os deveres me emprestavam o material".

Quando estava com 12 anos, suas irmãs fugiram de casa enquanto ela estava na escola. A partir daí seu sofrimento aumentou.

Aos 14 anos saiu da escola e foi trabalhar na casa de uma senhora que a tratava bem e lhe dava comida e roupas, coisas que não tinha em casa. Ficou nesta casa durante 5 anos. Aos 19 anos resolveu vir para Salvador ficar com a mãe: "chegou a hora de eu encarar o mundo. Se ficar aqui com meu pai vou morrer".

Aos 20 anos casou e teve 3 filhas. Seu marido vivia de biscates e bebia muito; depois de algum tempo abandonou-as. A única coisa que fez foi dar-lhes um barraco na invasão.

Da convivência com sua família de origem diz que suas lembranças são muito tristes mas, apesar de tudo, também trouxe coisas positivas que passa para suas filhas como respeitar e viver bem com as pessoas e a importância dos estudos.

Para Lúcia "como fui boa filha sou boa mãe"; dá carinho e conselho para as filhas, "só não dou o que não posso".

Atualmente vive da pesca e lava roupa; as filhas só a ajudam quando não estão estudando.
Além de estar sempre atenta ao que se passa com as filhas, expressa com palavras o carinho que sente por elas dizendo "não tem nada nesse mundo que eu amo, depois de Deus, mais que vocês".

O que ela valoriza muito são suas três filhas e a presença de Deus na sua vida "eu sei que Ele nunca me deixa sozinha".

\section{Diálogos pertinentes}

Lúcia mostrou que, apesar de todos os reveses pelos quais passou e passa, conseguiu elaborá-los e dar um significado à sua vida e à de suas filhas. Tem como projeto atual de vida melhorar sua casa ou se mudar e, para suas filhas, que estudem para que possam conseguir um emprego.

Lúcia não guarda rancor de seu pai, compreendendo que ele descontava nos filhos a raiva que sentia da mãe, e construiu seu próprio modelo de lidar com as filhas. Lúcia exemplifica assim Walsh ${ }^{13}$, para quem "a qualidade de ser resiliente capacita as pessoas a lidar com suas dores, tomar conta de suas vidas e seguir em frente, vivendo e amando plenamente".

Formou uma rede social de apoio com seus vizinhos, com seus colegas de escola que lhe emprestavam material escolar para que ela pudesse estudar e fazer os deveres que a professora passava. Com isso, sobreviveu à violência do pai, além de ter tido a compreensão de que precisava fazer alguma coisa por ela mesma, necessitando sair do convívio paterno para "sobreviver".

Lúcia, até os seis anos de idade vivia, segundo suas palavras, num ambiente harmonioso, o que deve ter sido fundamental para ter desenvolvido forças (resiliência) para enfrentar as adversidades que vieram depois que sua mãe foi embora. A forma como seu pai passou a se relacionar com sua mãe, depois desse episódio, afetou profundamente a maneira dele se relacionar com os filhos, o que está de acordo 
com Lewis 9 . A partir daquele momento, Lúcia e seus irmãos perderam o apoio de ambos e passaram a contar somente com alguns parentes que moravam próximos e vizinhos, sem o conhecimento do pai pois este não queria a ajuda de ninguém.

Reconhece e valoriza, contudo o pai por tê-la mandado para a escola, embora não lhe desse nenhum material escolar e a maltratasse constantemente.

$\mathrm{Na}$ sua história não transparece ressentimento; pelo contrário, parece compreender o que aconteceu e não coloca seu pai como seu algoz, mas como uma vítima das circunstâncias.

Ultrapassou essas dificuldades graças à sua habilidade em formar redes de apoio que lhe deram suporte para seu desenvolvimento físico, ao lhe fornecerem alimento e o básico para sobreviver.

Quando chegou à Salvador, Lúcia constatou uma situação de equivalente dificuldade, ficando indecisa quanto a ficar ou retornar. Optou por ficar a fim de poder ajudar a mãe.

É importante assinalar como as condições adversas na vida de Lúcia a levaram a desenvolver habilidades sociais como a colaboração, a solidariedade, a reciprocidade, e generosidade em relação a ajudar o próximo.

Em Salvador, não ficou de braços cruzados e fez com que as oportunidades aparecessem e, quando estas chegaram, tratou de agarrá-las, atitude que manteve até o momento da entrevista e que se evidenciou nas estratégias que usava para conseguir dinheiro para o seu sustento e das filhas, como por exemplo, ao não conseguir vender os mariscos que pescava, trocava-os na venda por comida, "faço um jogo".

A história de Lúcia evidencia, segundo Seligman $^{8}$, de que ao longo dos anos pode-se superar o desamparo (é o estado de coisas em que nada do que se propõe fazer afeta o que lhe acontece) e conquistar o controle pessoal, que é a capacidade de modificar as coisas pela ação voluntária de cada um: é o oposto da im- passibilidade (p. 17)

\section{Considerações a partir das cinco entrevistadas}

As cinco entrevistadas, do mesmo modo que o caso relatado como exemplo, tiveram uma infância bastante conturbada, com pouca atenção dos adultos mais próximos o que, no entanto, parece ter sido a motivação principal para o desenvolvimento de um comportamento resiliente; isto é, perceberam, desde muito cedo, que elas mesmas é que teriam que se cuidar, além de cuidar da casa, dos irmãos e, muitas vezes, até mesmo, dos pais.

Assim, as entrevistadas apresentaram um aspecto em comum em suas vidas: a percepção de estar em uma situação limite e de que podiam, por sua própria ação, dirigir o seu destino. Por meio de uma realização precoce de suas potencialidades, adquiriram confiança em si mesmas e na sua capacidade de encontrar caminhos viáveis, além da persistência; ou seja, a auto-confiança parece estar ligada à criatividade e a traços de obstinação.

No entanto, as cinco mulheres tiveram, em algum momento da sua trajetória de vida, alguém, ou até mesmo uma comunidade, que as valorizou e, com isso, re-afirmou-as e ao seu comportamento. Mostraram ter pontos de apoio de valência positiva que, do seu passado, permitiram que construíssem pontes em relação a um futuro, apropriando-se das circunstâncias que se lhes apresentavam no presente ${ }^{14}$.

Cada uma das entrevistadas, durante essa trajetória, foi construindo seu próprio modelo de mãe e, com isto, desprendendo-se e/ou diferenciando-se, em alguma medida, do passado. Não reproduziram os modelos, mas mantiveram deles algo que as manteve enraizadas e, com isto, conseguiram re-significar experiências, dolorosas e difíceis.

Dentro dessa dinâmica, dois traços sobressaíram: o não ter ressentimento e o manter 
o humor.

Assim, do ponto de vista de riscos e proteção e da relação meio interno / meio externo, observamos como os modos de partilhar precoce e intensamente exercidos forneceram não apenas a base, mas também a força e a vontade com que se lançaram posteriormente a outros momentos de sua vida. Conforme Bastos ${ }^{15}$, a integração familiar é favorecida por meio do envolvimento de seus membros nas atividades domésticas e no compartilhamento de experiências comuns - denominados modos de partilhar-e, na vivência que essas cinco mães tiveram na infância e adolescência, embora tivessem que trabalhar fora de casa, todas tiveram tarefas como cuidar da própria casa, dos irmãos e até muitas vezes dos pais como já foi dito.

Por meio de atitudes e cuidados com os filhos, deram a eles valores que trouxeram de sua família e os que construíram. Por exemplo: manter a família unida e participativa, ensinando o valor do estudo e de se cumprir com as obrigações que, no caso, foi a de estudar. Apesar das dificuldades financeiras por que passaram, situação comum às cinco, não permitiram que os filhos deixassem os estudos para ir trabalhar na rua ou até mesmo em casa.

\section{CONSIDERAÇÕES FINAIS}

Este estudo evidenciou que, ao lado da presença de algumas das características da resiliência conforme a literatura, como senso de humor, auto-imagem positiva, perseverança, crença no futuro, a resiliência das participantes parece ter sido forjada no sofrimento e no trabalho duro, tendo as mesmas percebido, desde muito cedo, que se não lutassem por si mesmas, teriam poucas oportunidades de desenvolvimento satisfatório. Tais mulheres não preencheram, como enfoca a literatura, uma série de requisitos para que o comportamento resiliente ocorresse; no entanto, desenvolveram uma "resiliência de sobrevivência" alicerçada sobre o próprio desempenho, em que as dificuldades se tornaram meios para o seu sucesso como pessoa.

Deste modo, a relação interna/externa quanto à capacidade dita de resiliência poderia ser assim expressa: o esforço e o sofrimento as tornaram capazes de suportar o esforço e o sofrimento e a encontrar um caminho viável onde outros não o vêem.

A dureza de sua condição de crescimento e desenvolvimento tornou-as duras. Aflexibilidade ocorreu nos pontos acima descritos: na criação de pontes que forneceram vínculos entre o passado e o presente, assentando um caminho real presente.

Em parte em decorrência das situações vividas na infância, em parte em conseqüência dos pontos acima apontados, foram capazes de atualizar redes sociais de apoio, de vários tipos, duração, intensidade, etc. As redes de apoio estiveram presentes em todas as histórias, possibilitando a sobrevivência da família de origem quando criança e, quando adultas, elas próprias sendo a rede para os seus filhos, netos, afilhados, vizinhos.

Finalmente essas mulheres mostravam diariamente a seus filhos como sobreviver de maneira digna - em um ambiente de risco no qual vivem - por saber selecionar os lugares que frequientavam, assim como as pessoas em quem podiam confiar, em suma, sem se isolarem, mas sendo prudentes. De acordo com Vanistendael ${ }^{1}$ (p.13), "a resiliência, na vida real, exige alguma forma de referência moral".

\footnotetext{
Abstract: This is a qualitative and exploratory study that aim to characterize the personal and contextual resources used by women considered "resilient" for their ability to overcome, in a social positive way, adversities such as: abandonment, violence, unemployment and disease. The study attempts to identify how these women, when they themselves were children and adolescents, perceived and explored their own environment and how this environment in which
} 
they grew up in functioned within the world around them and the opportunities it offered. Furthermore, what personal and contextual resources they were able to utilize in this environment. The study chose five participants from a group named "Conversa de família" (Talk about family), located in an Educative Center, in a suburb of Salvador, Bahia. The researchers applied a semistructured interview about the life history and the sociometric network. The analysis was based on an ecological perspective of human development, which considers the person in context and developmental processes in time, as well as the Psychodramatic approach. The results of the study indicated a "resilience of survival", based on their own performance, where the difficulties were the means for their success as people. The study also revealed the presence of real or imaginary figures, and the importance for these women to have a relational networks, inside and/ or outside the family, as well as the possibility for these women of move in this network, so these forms of relationships could functioning as a basis for future relationships. Some common features appeared in the study: confidence in themselves and in their capacity to find viable ways to cope, persistence, a good self image, not to have feelings of resentment and to have a good humor. The supportive networks are present in all histories, making possible for the survival of the original family, and then her own survival and, as adults, they themselves have been the network to her sons, grandsons, godsons, neighbors.

Key-words: Resilience. Context. Attachment. Development. Family.

\section{REFERÊNCIAS}

1. Vanistendael S. Resiliência: como crescer superando os percalços. Trad. José Claret Leite Cintra. Genebra: Escritório Internacional Católico da Infância; 1997.

2. Bowlby J. Uma abordagem de sistemas de controle para o comportamento de apego. In: Bowlby J. Apego. $2^{\mathrm{a}}$ ed. São Paulo: Martins Fontes; 2002. p. 291-319. v. I (Trilogia: Apego, Separaçãoe Perda).

3. Rutter M, Rutter M. Developing minds: challenge and continuity across the life span. London: Penguin Books; 1992.

4. Vasconcellos V, Valsiner J. Perspectiva coconstrutivista na psicologia e na educação. Porto Alegre: Artes Médicas; 1995.

5. Bowlby J. Por que as famílias fracassam? In: Bowlby J. Cuidados maternos e saúde mental. São Paulo: Martins Fonte; 1981. p. 79-91.

6. Moreno J L. Teoria e prática dos papéis. In: Instituto Fernandes FigueiraMoreno JL. Psicodrama. 2. ed. São Paulo: Cultrix; 1975. p. 206-30.

7. Bronfenbrenner U. Elementos do ambiente. In: Bronfenbrenner U. A ecologia do desenvolvimen to humano: experimentos naturais e planejados. Tradução de Maria Adriana Veríssimo Veronese. Porto Alegre: Artes Médicas; 1996. p. 37-83.
8. Seligman MEP. Aprenda a ser otimista. Tradução de Alberto Lopes. Rio de Janeiro: Record; 1992.

9. Lewis M. Alterando o destino: por que o passado não prediz o futuro. Tradução de Dinah de Abreu Azevedo. São Paulo: Moderna; 1999.

10. Masten AS, Garmezy N. Risk, vulnerability, and protective factors in developmental psychopathology. In: Lahey BB, Kasdin AE (organizadores). Advances in clinical child psychology. vol. 8. New York: Plenum Press; 1985.

11. Kaloustian S M. (organizador). Família brasileira, a base de tudo. $2^{a}$ ed. São Paulo: Cortez; 1994.

12. Yunes MAM, Szymanski H. Resiliência: noção, conceitos afins e considerações críticas. In: Tavares J (organizador). Resiliência e educação. São Paulo: Cortez; 2001. p. 13-42.

13. Walsh F. Strengthening family resilience. New York: The Guilford Press; 1998.

14. Alvarez AmdS, Moraes MCLd, Rabinovich EP. Resiliência: um estudo com brasileiros institucionalizados. Revista Bras Cresc Desenv Hum 1998; 8(1/2): 70-5.

15. Bastos ACdS. A estruturação cultural da família como contexto de desenvolvimento e a promoção da responsabilidade na criança. In: Bastos AcdS. Modos de partilhar: a criança e o cotidiano da família. Taubaté: Cabral Editora Universitá ria; 2001. p. 67-117. 